\title{
Comparison of PGE2 gel alone versus sequential use of Foley's catheter and PGE2 gel in the ripening of unfavorable cervix: a retrospective study
}

\author{
Veena Kadadanamari Shankarappa*, Preethi Natarajan, Monisha Natarajan
}

Department of Obstetrics and Gynecology, Sri Manakula Vinayagar Medical College and Hospital, Pondicherry, India

Received: 15 November 2020

Accepted: 01 December 2020

*Correspondence:

Dr. Veena Kadadanamari Shankarappa,

E-mail: ssykid2003@yahoo.co.uk

Copyright: ( $\odot$ the author(s), publisher and licensee Medip Academy. This is an open-access article distributed under the terms of the Creative Commons Attribution Non-Commercial License, which permits unrestricted non-commercial use, distribution, and reproduction in any medium, provided the original work is properly cited.

\begin{abstract}
Background: Induction of labor is common procedure practiced in obstetrics. Various methods used for cervical ripening are lacking the proven superiority of one over other. Our study aimed at comparing intracervical PGE2 gel used alone with sequential use of Foley's catheter and PGE2 gel in order to appreciate reduction in LSCS rate without affecting neonatal outcome.

Methods: The retrospective study was conducted among cases delivered with labor induction between June 2017 to January 2019. Among 104 pregnant women, group1 had received PGE2 gel alone and group 2 had received Foley's followed by PGE2 gel for induction. The primary outcome included Cesarean section rate and secondary outcomes included improvement in Bishop scores, induction to delivery interval, indication for LSCS, APGAR scores, NICU admission. Data was analyzed and compared.

Results: Both groups were comparable with respect to maternal age, gestational age and indication for induction. There was no significant difference in the mean pre-induction Bishop score between groups. Mean IDI was higher in group 2. There was no difference in mode of delivery, neonatal and maternal morbidity between groups. Higher number of women went into spontaneous labor among group 2 and higher number of women needed oxytocin among group 1 for augmentation.

Conclusions: Intra cervical PGE2 can be safely used among women with unfavorable cervix to achieve faster delivery without increasing LSCS rate. Whereas sequential use of Foley's catheter and PGE2 gel can be safer alternative for induction of delivery with low risk of oxytocin augmentation when quicker delivery is not needed.
\end{abstract}

Keywords: PGE2 gel, LSCS, Foley's catheter, Induction of labor

\section{INTRODUCTION}

Induction of labor is indicated when continuation of pregnancy is not beneficial to fetus and may harm the fetus or mother. Status of the cervix determines the success of induction. Several methods are used to ripen the cervix prior to initiation of contractions. Soft, anterior and effaced cervix dilates better compared to firm cervix. Mechanical methods such as Foleys catheter and double balloon stretch the cervix by the pressure on internal os and cervical canal, whereas prostaglandins mimic physiological cervical ripening and prepare the myometrium for uterine contraction. Unlike prostaglandins, mechanical methods less likely to cause hyper stimulation but increase induction to delivery interval. Although many methods are used to ripen the cervix, superiority of any one method is not proven.

Caesarean section cause substantial risk in index pregnancy as well as future pregnancy. Increased risk of caesarean section is one of the major concerns when compared with the spontaneous labor. Of primigravida 
women undergoing induction of labor, $29.3 \%$ deliver by Caesarean section; this is double the rate of those with spontaneous onset of labor $(14.2 \%){ }^{1}$

Cervical ripening lower the rate of LSCS compare to labor induction without ripening. Carbone et al supported the use of more than one method concurrently or consecutively for ripening of cervix. ${ }^{2}$ Present study aimed at comparing intra cervical PGE2 gel used alone with sequential use of Foley's catheter and PGE2 gel in order to see if sequential use results in reduction in LSCS rate without affecting neonatal outcome.

\section{METHODS}

This was a retrospective observational comparative study conducted among the patients admitted to Hospital between June 2017- January 2019 with singleton pregnancy in cephalic presentation at term with unfavorable cervix (Bishop Score<6) planned for induction of labor. According to hospital protocols, two methods were followed for induction. First being, using maximum 3 PGE2 gels intracervically with 6 hours apart until Bishop score is $>6$ or regular painful contractions less than 5 minutes apart had commenced. Other method being, using Foley's catheter intracervically for 24 hours followed by intracervical gel till Bishop score of $>6$ is reached. In case of Foley's catheter expelled before 24 hours, intracervical gel will be used till sufficient bishop score is reached.

Case sheets were collected from Medical Record Department. Patients with preterm, non-cephalic presentation, multiple pregnancy, IUGR, previous LSCS, bishop score $>6$, fetal anomaly, severe preeclampsia/eclampsia, antepartum hemorrhage, parity $>4$, PROM and IUD were excluded from the study. Patients with incomplete data were excluded from the study. Data was collected into 2 groups.
Group 1 included 52 patients who were induced using intracervical PGE2 gel alone and group 2 included 52 patients who underwent Foley's ripening prior to PGE2 gel. Data of demographic details, parity, indications for induction of labor (IOL), bishop score, induction to delivery interval (IDI), improvement in bishop scores, mode of delivery, indication for operative delivery, birth APGAR, birth weight and neonatal admission to NICU were collected from case sheets. The primary outcome included Cesarean section rate and secondary outcomes included improvement in BISHOP Scores, induction to delivery interval, indication for LSCS, postpartum hemorrhage, wound infection, APGAR scores, NICU admission and duration of NICU stay. Data was analyzed and compared between the two groups.

\section{Statistical analysis}

The variables with normal distributions were compared between the groups using independent samples tests. The Mann-Whitney U-test was applied to the variables without normal distribution. The categorical data was analyzed by the Pearson's Chi-square test, and the Fisher's exact test was applied if the expected frequency is less than 5 in $>20 \%$ of all cells. The variables normally distributed were expressed as Mean/SD and the categorical variables were presented as the number of cases and percentage. $P$ values $<0.05$ was considered to be statistically significant. SPSS for Windows version 17 was used for the statistical analyses.

\section{RESULTS}

Total 158 cases were induced for labor between June 2017 to January 2019. After excluding the not eligible patients, 104 patients were included in the study. Among 104 patients, 52 were given PGE2 gel included in group 1 and 52 patients were given intracervical Foley's followed by PGE2 gel were included into group 2.

Table 1: Demographic details and indications for induction of labor.

\begin{tabular}{|c|c|c|c|}
\hline Baseline characteristic & Group1 (only PGE2gel) & Group 2 (Foley with PGE2 gel) & P value \\
\hline Age $($ Mean \pm SD) & $24.10 \pm 3.34$ & $25.60 \pm 4.62$ & $0.0606(\mathrm{NS})$ \\
\hline Range & $19-32$ & $18-40$ & \\
\hline \multicolumn{4}{|l|}{ Parity } \\
\hline Primigravidas & $34(65.40)$ & $34(65.40)$ & \multirow{2}{*}{ NS } \\
\hline Multigravida & $18(34.60)$ & $18(34.60)$ & \\
\hline \multicolumn{4}{|c|}{ Mean POG at IOL (weeks) range } \\
\hline $36+1$ to 40 & 27 & 33 & \multirow{3}{*}{0.2337 (NS) } \\
\hline $40+1$ to 42 & 25 & 19 & \\
\hline$>42$ & 0 & 0 & \\
\hline \multicolumn{4}{|l|}{ Indication for IOL } \\
\hline Fetal growth restriction & $2(3.85 \%)$ & $1(1.92 \%)$ & 0.34 \\
\hline Hypertensive disorder & $8(15.39 \%)$ & $14(26.92 \%)$ & 0.15 \\
\hline Post-dated pregnancy & $32(61.54 \%)$ & $23(44.23 \%)$ & 0.07 \\
\hline GDM & $2(3.85 \%)$ & $3(5.77 \%)$ & 0.65 \\
\hline Oligohydramnios & $8(15.38 \%)$ & $9(17.31 \%)$ & 0.79 \\
\hline
\end{tabular}


Table 2: Pre- and post-ripening Bishop score, no. of PGE2 gels required, cervical ripening time, oxytocin requirement, mode of delivery and indications for caesarean section.

\begin{tabular}{|c|c|c|c|}
\hline \multicolumn{4}{|l|}{ Bishop score } \\
\hline Pre ripening Bishop score $($ Mean \pm SD) & $2.5 \pm 1.45$ & $2.38 \pm 0.56$ & $0.5789(\mathrm{NS})$ \\
\hline $\begin{array}{l}\text { Post ripening Bishop score (Mean } \pm \text { SD) } \\
\text { (After Gel } 1 \text { in group I and Foley's in group II) }\end{array}$ & $6.19 \pm 3.09$ & $5.94 \pm 1.80$ & $0.6153(\mathrm{NS})$ \\
\hline Spontaneous onset of labor & $12(23.07)$ & $30(57.69)$ & 0.000086 \\
\hline Accelerated with oxytocin & $35(67.30)$ & $18(34.67)$ & 0.000854 \\
\hline Underwent LSCS on maternal request before labor onset & $5(9.61)$ & $4(7.69)$ & $0.727265(\mathrm{NS})$ \\
\hline \multicolumn{4}{|l|}{ Mode of delivery } \\
\hline Caesarean delivery & $21(40.38 \%)$ & $22(42.31 \%)$ & $0.9335(\mathrm{NS})$ \\
\hline Vaginal delivery & $31(59.62 \%)$ & $29(55.77 \%)$ & $0.8427(\mathrm{NS})$ \\
\hline Instrumental delivery & 0 & $1(1.92 \%)$ & $1.0000(\mathrm{NS})$ \\
\hline \multicolumn{4}{|l|}{ Indications for caesarean section } \\
\hline Pathological CTG & $6(11.53 \%)$ & $9(17.03 \%)$ & $0.7716(\mathrm{NS})$ \\
\hline Meconium stained liquor (MSL) & $2(3.84 \%)$ & $3(5.76 \%)$ & $0.9215(\mathrm{NS})$ \\
\hline Failed induction of labor (IOL) & $5(9.61 \%)$ & $3(5.76 \%)$ & $0.7454(\mathrm{NS})$ \\
\hline Non-progress of labor (NPL) & $3(5.76 \%)$ & $3(5.76 \%)$ & $0.7021(\mathrm{NS})$ \\
\hline Maternal request (MR) & $5(9.61 \%)$ & $4(7.69 \%)$ & $1.0000(\mathrm{NS})$ \\
\hline
\end{tabular}

Table 3: Induction-delivery interval (IDI) of the women who delivered vaginally and neonatal outcome.

\begin{tabular}{|c|c|c|c|}
\hline Induction-delivery interval (min.) & Group 1 & Group 2 & P value \\
\hline IDI (Mean \pm SD) (among normally delivered women) & $13.56 \pm 7.1$ & $28.01 \pm 12.14$ & $\mathrm{P}<0.0001$ \\
\hline Proportion of women delivering vaginally & $\mathrm{N}=31$ & $\mathrm{~N}=29$ & \\
\hline Delivery within 12 & $2(6.4)$ & $1(3.44)$ & 0.952739 \\
\hline Delivery within $12.01-24 \mathrm{~h}$ & $24(77.41)$ & $15(51.72)$ & 0.069605 \\
\hline Delivery $>24 \mathrm{~h}$ & $5(16.1)$ & $13(44.8)$ & 0.015345 \\
\hline \multicolumn{4}{|l|}{ Neonatal outcome } \\
\hline Birth weight $(\mathrm{kg})$ & $3.04 \pm 0.42$ & $3.02 \pm 0.37$ & 0.7972 \\
\hline Range & $2.20-4.50$ & $2.20-4.00$ & $(\mathrm{NS})$ \\
\hline Apgar score at $1 \mathrm{~min}$ & $7.62 \pm 0.68$ & $7.65 \pm 0.81$ & \\
\hline Apgar score at $5 \mathrm{~min}$ & $9.44 \pm 0.13$ & $8.81 \pm 0.79$ & 0.8383 \\
\hline (NICU) admission & 10 & 8 & (NS) \\
\hline \multirow[t]{2}{*}{ NICU stay (average) } & 3.40 & 3.90 & 0.0001 \\
\hline & & & 0.604182 \\
\hline
\end{tabular}

Table 1 shows the demographic details of patients which included age, parity, period of gestation and indications for IOL among women who were included in this study. There was no significant difference among two groups among these parameters.

Table 2 shows the pre- and post-ripening Bishop Score, requirement of oxytocin for acceleration, mode of delivery and the indications for CS in the two groups. The mean pre induction Bishop score among 2 groups was similar. Mean Bishop score after first gel in group 1 and after expulsion of Foley's catheter or 24 hours after Foley's ripening among group 2 were similar.

The indications for CS were also comparable in the two groups, the commonest being a pathological CTG. Total of 84 PGE2 gels were used in group 1 whereas only 54 were used for group 2. Significantly higher number of women went into spontaneous labor among group 2 and higher number of women needed oxytocin among group 1 for augmentation of labor. Women opting for LSCS for maternal request were similar among 2 groups.

Table 3 describes the IDI among women who delivered vaginally and the neonatal outcome.

The IDI was calculated from insertion of Foley until delivery. Mean IDI was significantly higher in Group 2. The proportion of women who delivered within 12 hours of induction was similar in both groups. Significantly a greater number of women took $>24$ to deliver in group 2 compare to group 1. 21 among 23 cases of LSCS occurred within 12 hours among group 1 whereas 16 among 22 cases of LSCS occurred after 24 hours Foley's induction among group 2. There was no difference among birth weight and 1st minute APGAR score among 
two groups but fifth minute APGAR score was significantly lower among group 2. Neonatal outcome in terms of NICU admissions and average days of stay was comparable among 2 groups.

Here, 2 patients with episiotomy and 1 patient with LSCS had wound infection in group 1 whereas 4 patients with episiotomy and 2 patients with LSCS had wound infection in group 2. Postpartum hemorrhage was seen in 2 patients among group 1 and one patient in group 2 . Two patients had hyperstimulation in group 1 but none of them had hyperstimulation in group 2 .

\section{DISCUSSION}

Induction of labor aimed at uncomplicated vaginal delivery with minimal adverse fetomaternal outcome which begin with cervical ripening often. Our study aimed to study whether Foley's ripening prior to PGE2 reduce $\mathrm{LSCS}$ rate.

Comparison between Foley's and first PGE2 gel in terms of cervical ripening did not convene significant advantage over other. Although theoretical concerns regarding infection with use of Foley's is present our study did not reveal significant infectious comparatively. Similar results were observed in several studies. ${ }^{3}$

More than one third $(40.38 \%$ vs. $42.31 \%)$ of patients needed LSCS with no difference among two groups. Similar results were established by Pennell et al4, where they compared cervical ripening with single balloon, double balloon and PGE2 gel. Although some authors5 have observed high percentage of cesarean section due fetal distress among PGE2 group. Our study did not find any difference in indication for LSCS.

There was no difference in nursery admission rates between groups; however, measures of newborn wellbeing were significantly worse for women receiving prostaglandin gel. While no adverse reactions occurred with the single balloon catheter, PGE2 gel for cervical ripening was associated with increased rates of uterine hyper stimulation, FHR pattern abnormalities and an increased need to perform fetal scalp blood sampling.

There was no significant difference in NICU admissions among 2 groups but 5th minute APGAR scores were significantly lower in concurrent use of Foley's and PGE2 gel. Fetal scalp blood sampling was not done to confirm the level of acidosis.

Pennell et al found increased rates of respiratory acidosis after cervical ripening with PGE2 gel compare to single and double balloon use probably due to hyper stimulation. We did not have find significant difference in occurrence of fetal distress among 2 groups. ${ }^{4}$

Induction delivery interval (IDI) is significantly higher in Foley's followed by PGE2 gel. Similar results were reported from other studies Boulvain $\mathrm{M}$ but some studies did not find difference. ${ }^{4-6}$ Chowdhary et al demonstrated that cervical ripening with the combined use of Foley and one dose of intracervical PGE2 $(0.5 \mathrm{mg})$ is superior to Foley alone in terms of reducing IDI without affecting the LSCS rate. ${ }^{7}$ Though IDI was less among PGE2 group significantly higher number of women went into spontaneous labor among Foley's group. Only 34.67\% of women were given oxytocin for augmentation of labor in combined group. Khamaiseh et al demonstrated that women requiring oxytocin and the duration of oxytocin were higher in the Foley catheter group compare to PGE2. ${ }^{5}$ We used PGE2 gel after Foley's catheter removal if cervix is unfavorable. Hence, we did not find this trend. Foley's catheter alone may be less efficient than PGE2 for initiating regular uterine contractions.

Number of women who took more than 24 hours to deliver was significantly lower among PGE2 gel group compare to Foley's ripening followed by PGE2 gel group. Meta-analysis conducted by $\mathrm{Li}$ et al did not find significant difference in terms of vaginal delivery in 24 hours or less among Foleys catheter group and PGE1 or PGE2 groups. ${ }^{8}$

\section{CONCLUSION}

Intra cervical PGE2 can be safely used among women with unfavorable cervix to achieve faster delivery without increasing LSCS rate. Whereas sequential use of Foley's catheter and PGE2 gel can be safer alternative for induction of delivery with low risk of oxytocin augmentation when quicker delivery is not needed.

\section{Funding: No funding sources \\ Conflict of interest: None declared}

Ethical approval: The study was approved by the Institutional Ethics Committee

\section{REFERENCES}

1. Better Outcomes Registry \& Network (BORN) Ontario. Perinatal Health Report 2009-2010. Waterloo Wellington and Hamilton Niagara Haldimand Brant-LHINs 3 \& 4. Ottawa ON: BORN; 2011.

2. Carbone JF, Tuuli MG, Fogertey PJ, Roehl KA, Macones GA. Combination of Foley bulb and vaginal misoprostol compared with vaginal misoprostol alone for cervical ripening and labor induction: a randomized controlled trial. Obstet Gynecol. 2013;121:247-5.

3. Deshmukh VL, Yelikar KA, Deshmukh AB. Comparative Study of Intra-cervical Foley's Catheter and PGE2 Gel for Pre-induction Ripening (Cervical). J Obstet Gynecol Ind. 2011;61(4):418-21.

4. Pennell C, Henderson J, O’Neill M, McCleery S, Doherty D, Dickinson J. Induction of labor in nulliparous women with an unfavorable cervix: A randomized controlled trial comparing double and 
single balloon catheters and PGE2 gel. Int J Obstet Gynaecol. 2009;116:1443-52.

5. Khamaiseh K, Al-Ma'ani W, Abdalla I. Prostaglandin E2 versus Foley catheter balloon for induction of labor at term: a randomized controlled study. J Raman Mathemat Soc. 2012;19:42-7.

6. Boulvain M, Kelly A, Lohse C, Stan C, Irion O. Mechanical methods for induction of labor. Cochrane Database Syst Rev. 2012;3:297-9.

7. Chowdhary A, Baggaa R, Kalraa J, Jaina V, Sahaa SC, Kumarb P. Comparison of intracervical Foley catheter used alone or combined with a single dose of dinoprostone gel for cervical ripening: a randomized study. J Obstet Gynecol. 2019;39(4):461-7.

8. Li Y, He Z, Song L, Zhang J, Wang J, Cheng J, Foley catheter balloon versus prostaglandins for cervical ripening and labor induction: a systematic review and meta-analysis. Int $\mathbf{J}$ Clin Exp Med. 2016;9(4):7573-84.

Cite this article as: Shankarappa VK, Natarajan P, Natarajan M. Comparison of PGE2 gel alone versus sequential use of Foley's catheter and PGE2 gel in the ripening of unfavorable cervix: a retrospective study. Int J Reprod Contracept Obstet Gynecol 2021;10:127-31. 